\title{
EBOV-RNA test with RT-PCR in ocular fluids of Ebola survivors can help to safely perform cataract surgery
}

\author{
Leopoldo Spadea, Nicola Iozzo
}

Head Eye Clinic "Policlinico Umberto I" Hospital, "Sapienza” University of Rome, Viale del Policlinico, Rome, Italy

Correspondence to: Leopoldo Spadea, MD. Head Eye Clinic "Policlinico Umberto I" Hospital, "Sapienza” University of Rome, Viale del Policlinico, 15500161 Rome, Italy. Email: leopoldo.spadea@uniroma1.it.

Comment on: Shantha JG, Mattia JG, Goba A, et al. Ebola Virus Persistence in Ocular Tissues and Fluids (EVICT) Study: Reverse TranscriptionPolymerase Chain Reaction and Cataract Surgery Outcomes of Ebola Survivors in Sierra Leone. EBioMedicine 2018;30:217-24.

Submitted Aug 29, 2018. Accepted for publication Sep 12, 2018.

doi: 10.21037/atm.2018.09.37

View this article at: http://dx.doi.org/10.21037/atm.2018.09.37

Since the Ebola virus (EBOV) was discovered in 1976, the recent 2014-2016 Ebola virus disease (EVD) outbreak in West Africa was the largest with 28,600 cases and about 11,300 deaths.

This epidemic started in Guinea and spread rapidly across the borders in Sierra Leone and Liberia (1).

After an incubation period of 2 to 21 days EBOV manifests clinically as a hemorrhagic fever that can lead to death by hypovolemic shock and multisystem failure generally within a month of infection.

Human-to-human transmission of EBOV occurs by direct contact (through cutaneous or mucosal lesions) with blood, secretions, organs or other body fluids of infected persons, and by indirect contact with environments contaminated with such fluids.

Although the West African epidemic has been declared formally extinguished in the spring of 2016, it has become increasingly clear that thousands of survivors remain at risk of post-EDV sequelae termed post-Ebola virus disease syndrome (PEVDS).

This term collects a group of physical and psychological symptoms affecting EVD survivors that include ocular disease, arthritis, hearing loss, abdominal pain and neuropsychiatric disorders as well as EBOV persistence in immune-privileged organs $(2,3)$.

Approximately $14-34 \%$ of survivors are at risk of having ocular complications during convalescence of which the most common is uveitis (4-6).

While acute inflammation causes pain, tearing and photophobia, chronic inflammation can lead to severe hypovision due to cataract or more rarely to other complications such as hypotonia and phthisis bulbi $(7,8)$.

Although it is not entirely clear how EBOV has been able to persist in the eye's privileged immune site, several studies suggest that the pathogenesis of ocular involvement results from the ability of EBOV to overcome the blood-retinal barrier and persist in retinal pigment epithelial cells.

Zeng and his team found EBOV-RNA in privileged immune sites such as vitreous cavities, brains and testes of rhesus macaques that survived the experimental Ebola infection. In contrast, in the monkeys that died during the acute phase, the virus was located mainly inside endothelial cells (9).

Smith and colleagues in their study published in in Translational Vision Science \& Technology introduced live EBOV to retinal pigment epithelium (RPE) cells in vitro. They observed that these cells are susceptible to infection by releasing high viral titers while continued their native function of expressing molecules that limit the ability of the immune system to fight infection(10).

Before the recent EDV broke out in West Africa it was thought that pathogenesis of uveitis may be a delayed hypersensitivity reaction to RNA viral antigens (11).

The recent case report published by Varkey et al. in the New England fournal of Medicine challenges this assumption.

They have described the discovery of EBOV RNA in the aqueous humor 100 days after the clearance of the virus from the blood and therefore this makes us believe that uveitis is a direct result of the lytic action virus (12).

Cataract are therefore the main cause of visual impairment in survivors but the ability of EBOV to persist in ocular fluids for an unknown duration causes that cataract surgery in these 
patients may be a potential risk of virus dissemination.

The manuscript of Shantha et al., reported in the journal EBioMedicine, "Ebola Virus Persistence in Ocular Tissues and Fluids (EVICT) Study: Reverse Transcription-Polymerase Chain Reaction and Cataract Surgery Outcomes of Ebola Survivors in Sierra Leone" is a cross-sectional study reported the clinical ophthalmic phenotypes, prevalence of EBOV RT-PCR in ocular fluid of a cohort of Sierra Leonean EVD survivors anticipating ocular surgery or with active uveitis (13).

The authors screened 137 EDV survivors of which 32 (23\%) were excluded: 16 showed an immature cataract, 11 retinal or nerve optic disease that precluding visual recovery while 5 had hypotony or phthisis bulbi.

Fifty EDV survivors (36\%) were enrolled into the EVICT study: 46 eyes (92\%) showed significant cataract, 2 eyes (4\%) active uveitis, 1 eye (2\%) subluxed lens and $1(2 \%)$ blind painful eye due to chronic uveitis.

The median age of survivors was 24 years and 35 (70\%) patients were female.

The authors also described how the survivors' eyes showed the typical characteristics of post-uveitic cataract such as white uveitic cataract, posterior subcapsular cataract or white cataract with the iris-lens synechiae.

Forty-six survivors (92\%) showed ocular signs due to a previous uveitis like posterior synechiae, keratic precipitates, band keratopathy and chorioretinal scars.

Therapies used before study enrollment included oral prednisone, topical prednisolone acetate and oral sulfamethoxazole/trimethoprim $800 \mathrm{mg} / 160 \mathrm{mg}$.

All 50 survivors underwent a sampling procedure of ocular fluid: 49 (98\%) had an anterior chamber paracentesis $(100-200 \mu \mathrm{L})$ and 1 patient had a vitreous tap $(500 \mu \mathrm{L})$; pre- and post-sampling procedures a conjunctival swab was obtained. However, the authors noted that ocular samples were obtained in full personal protective equipment following guidelines from the WHO and Emory Serious Communicable Diseases Unit (SCDU).

All samples of aqueous humor, vitreous, and conjunctive were negative for EBOV RNA by RT-PCR at a median of 19 months after EVD diagnosis in Phase I of ocular fluid sampling and at a median of 34 months after EVD in Phase 2 of ocular fluid sampling.

Therefore 46 patients with cataract were assessed as eligible for manual small incision cataract surgery (MSICS) and 34 (74\%) underwent MSICS with IOL implantation.

All patients did not have active eye inflammation at the time of surgery.

Twenty-four eyes (70\%) had a very low preoperative AV and met the concept of blindness based on the International Classification of Disease-10 (ICD-10).

The authors described how cataract surgery in survivors was followed by a great improvement in visual acuity that from a preoperative hand motion level passed to 20/70 after a month and 20/30 after 3-4 months from surgery.

The EVICT study is the first to methodically evaluate the persistence of EBOV in ocular fluids of survivors with cataract or active uveitis.

Although was limited in size the authors have shown how cataract surgery can be safely performed and with great visual performance results in all survivors tested negative for $\mathrm{EBOV}$ in their ocular fluid.

Although $92 \%$ of survivors have had a history of uveitis, this study cannot determine whether the virus was present during acute ocular inflammation.

Currently although vision loss due to cataract is a significant cause of disability in these patients, the World Health Organization cautions against elective surgery until research uncovers more about the persistence of the virus in body fluids (14).

Given that today there are about 10,000 survivors at risk of complications of uveitis it is desirable to develop appropriate indications and optimal protocols for intraocular surgery in these unfortunate patients. In fact vision restoration, after cataract surgery, can impact the quality of life of survivors who have already suffered so much due to the acute phase of EVD.

Moreover, the development of a more precise knowledge of ocular viral persistence and the establishment of appropriate guidelines for eye surgery will undoubtedly prove very useful for dealing with other infectious diseases including Dengue fever, West Nile, Zika, and yellow fever (15).

\section{Acknowledgements}

None.

\section{Footnote}

Conflicts of Interest: The authors have no conflicts of interest to declare.

\section{References}

1. World Health Organization. Ebola Situation Report. World Health Organization. Available online: http://who. int/csr/disease/ebola/en/ Accessed 10 June 2016. 
2. Nanyonga M, Saidu J, Ramsay A, Shindo N, Bausch DG. Sequelae of Ebola Virus Disease, Kenema District, Sierra Leone. Clin Infect Dis 2016;62:125-6.

3. Vetter P, Kaiser L, Schibler M, Ciglenecki I, Bausch DG. Sequelae of Ebola virus disease: the emergency within the emergency. Lancet Infect Dis 2016;16:e82-91.

4. Tiffany A, Vetter P, Mattia J, et al. Ebola Virus Disease Complications as Experienced by Survivors in Sierra Leone. Clin Infect Dis 2016;62:1360-6.

5. Shantha JG, Crozier I, Hayek BR, et al. Ophthalmic manifestations and causes of vision impairment in Ebola virus disease survivors in Monrovia, Liberia. Ophthalmology 2017;124:170-7.

6. Mattia JG, Vandy MJ, Chang JC, et al. Early clinical sequelae of Ebola virus disease in Sierra Leone: a crosssectional study. Lancet Infect Dis 2016;16:331-8.

7. Hereth-Hebert E, Bah MO, Etard JF, et al. Ocular complications in survivors of the Ebola outbreak in Guinea. Am J Ophthalmol 2017;175:114-21.

8. Steptoe PJ, Scott JT, Baxter JM, et al. Novel retinal lesion in Ebola survivors, Sierra Leone, 2016. Emerg Infect Dis 2017;23:1102-9.

9. Zeng X, Blancett CD, Koistinen KA, et al. Identification and pathological characterization of persistent asymptomatic Ebola virusinfection in rhesus monkeys. Nat

Cite this article as: Spadea L, Iozzo N. EBOV-RNA test with RT-PCR in ocular fluids of Ebola survivors can help to safely perform cataract surgery. Ann Transl Med 2018;6(Suppl 1):S29. doi: 10.21037/atm.2018.09.37
Microbiol 2017;2:17113.

10. Smith JR, Todd S, Ashander LM, et al. Retinal pigment epithelial cells are a potential reservoir for Ebola virus in the human eye. Transl Vis Sci Technol 2017;6:12.

11. Kibadi K, Mupapa K, Kuvula K, et al. Late ophthalmologic manifestations in survivors of the 1995 Ebola virus epidemic in Kikwit, Democratic Republic of the Congo. J Infect Dis 1999;179:S13-4.

12. Varkey JB, Shantha JG, Crozier I, et al. Persistence of Ebola virus in ocular fluid during convalescence. $\mathrm{N}$ Engl J Med 2015;372:2423-7.

13. Shantha JG, Mattia JG, Goba A, et al. Ebola Virus Persistence in Ocular Tissues and Fluids (EVICT) Study: Reverse Transcription-Polymerase Chain Reaction and Cataract Surgery Outcomes of Ebola Survivors in Sierra Leone. EBioMedicine 2018;30:217-24.

14. World Health Organization. Interim guidance Clinical care for survivors of Ebola virus disease. Available online: http:// apps.who.int/iris/bitstream/handle/10665/204235/WHO_ EVD_OHE_PED_16.1_eng.pdf

15. Merlea H, Donnioa A, Jean-Charlesa A et al. Ocular manifestations of emerging arboviruses: Dengue fever, Chikungunya, Zika virus, West Nile virus, and yellow fever. J Fr Ophtalmol 2018. pii: S0181-5512(18)30284-5. 